\title{
Mixed integer linear programming model for dynamic supplier selection problem considering discounts
}

\author{
Purnawan Adi Wicaksono ${ }^{1 *}$, I Nyoman Pujawan ${ }^{2}$, Erwin Widodo ${ }^{2}$, Sutrisno $^{3}$, and Laila Izzatunnisa $^{1}$ \\ ${ }^{1}$ Department of Industrial Engineering Diponegoro University, Semarang 50275 Indonesia \\ ${ }^{2}$ Department of Industrial Engineering, Sepuluh Nopember Institute of Technology, Surabaya 60111 Indonesia \\ ${ }^{3}$ Department of Mathematics, Diponegoro University, Semarang 50275 Indonesia
}

\begin{abstract}
Supplier selection is one of the most important elements in supply chain management. This function involves evaluation of many factors such as, material costs, transportation costs, quality, delays, supplier capacity, storage capacity and others. Each of these factors varies with time, therefore, supplier identified for one period is not necessarily be same for the next period to supply the same product. So, mixed integer linear programming (MILP) was developed to overcome the dynamic supplier selection problem (DSSP). In this paper, a mixed integer linear programming model is built to solve the lot-sizing problem with multiple suppliers, multiple periods, multiple products and quantity discounts. The buyer has to make a decision for some products which will be supplied by some suppliers for some periods cosidering by discount. To validate the MILP model with randomly generated data. The model is solved by Lingo 16 .
\end{abstract}

\section{Introduction}

In a highly competitive industry today, firms must realize the importance of supplier selection that meet the required quality and time. Firms are now facing increased consumer demand, shorter product life cycles, and sharper price cuts. This condition causes firms to cut costs and improve supply chain. Supply chain improvements become critical in rising the competitiveness of the firm. It can be done through supplier selection process (Sagar, 2012).

Fluctuative and dynamic demand make it difficult for firms to determine the order quantity and and when the order must be made to fulfill the demand and minimize the inventory costs. Suppliers are also expected to be dynamic as well. This can happen because a firm usually has a demand regarding supplier capacity, quality level, lead time, unit cost part, and time-varied fixed transportation cost. (Ware et al., 2014). Supplier selection problems are usually classified in terms of multi-echelon, multi-product, multi-supplier and the time period's nature (Lin \& Lei, 2009). Firm's requests always fluctuate so that time value requirements are considered dynamic, not with short or long-term agreements. Therefore, this paper will discuss Dynamic Supplier Selection Problem (DSSP). In DSSP which a set of suppliers is selected supplier for each period. (Ware et al., 2014).

Most of the models that have been developed for supplier selection problems ignore transportation elements that significantly impact the total procurement costs. (Wicaksono et al., 2016). However, there are already some researchers who consider transportation costs in the selection of single product suppliers such as
(Burke et al., 2007; Liao \& Rittscher, 2007; Aguezzoul, A., \& Ladet, 2007; Choudhary \& Shankar, 2011; Choudhary \& Shankar, 2013). Some researchers are choosing suppliers with multi-period, multi-product and multi-supplier (Rezaei \& Davoodi, 2011; Ware et al., 2014; Wicaksono et al., 2016). In another case, the supplier provides discounts for each purchase in large quantities to increase sales of a product goods / services. With discounts, buyers may be interested to buy a product. In practice, ordering in large amount with far distance can reduce transportation costs per unit (Shinn et al., 1996). Therefore, this study will develop a model that integrates procurement decisions with transportation costs and discounts.

To minimize procurement expenditures, purchasing and transportation costs need to be considered. Suppliers offer total cost discount and transportation costs based on trucking rates. The goal is to select several suppliers in fulfilling the demand of the product with a minimum total cost. In this paper, the researcher will make a model to solve supplier selection problem with multi-period, multiproduct and multi-supplier condition based on the development of the previous model (Ware et al., 2014) with discount consideration. The method used is Mixed Integer Linear Programming (MILP). Random data used for model validation. This model then solved using LINGO 16 software.

Furthermore, in part 2 of this paper, a brief literature review of models or techniques related to the dynamic supplier selection will be presented. Section 3 will present the model and its mathematical formulation. Section 4 will present a case study to test the proposed model. Finally, section 5 will provide conclusions and

\footnotetext{
*Corresponding author: purnawan@undip.ac.id
} 
suggestions for further research.

\section{Literature Review}

In supplier selection, there are two categories: quantitative model and qualitative model. Quantitative model includes linear programming, MILP, MINLP, dynamic programming, and multi-objective programming (Masella \& Rangone, 2000; Demirtas \& Üstün, 2008). Masella \& Rangone (2000) propose four supplier selections that are time and content based (logistics or strategic). Cakravastia (2004) propose a multi-objective model for supplier selection and consider the impact of decisions to be made.

Treviño-Garza et al., (2015) presented MILP for multi-product and multi-period to solve supplier selection problem. Ware et al., (2014) developed MINLP to address the issue of dynamic supplier selection (DSSP). Transportation costs have a large impact in procurement decisions, such as dividing orders on some suppliers will beresulting less quantity of goods and greater transportation costs (Aguezzoul \& Ladet, 2007). Wicaksono et al., (2016) studied DSSP considering truckload shipping using MILP.

Considering discount in supplier selection is important because discount can affect the decision of supplier selection (Chaudhry et al., 1993). Howefer, limited paper especially in DSSP consider discount in there model. There are two types of discounts: quantity discount and volume discount. In quantity discounts, product sales do not affect the price and discounts of other products. This discount strategy can be either incremental or all-unit. The linear programming model considers various prices including quantity discounts and inflated prices according to the number of orders (Aissaoui et al., 2007).

The supplier selection process for DSSP involves higher complexity in terms of selecting suppliers for all periods to produce the minimum total cost with the shortest lead time and meet the desired quality level for each product set by the company. In addition, to the best author knowledge there is not DSSP paper considering discount. Therefore, this paper will present a MILP formulation for DSSP by considering transportation costs and discount if multi-period, multi-product and multisupplier conditions.

\section{Model Development}

The problem can be explained briefly as follows: in a procurement management, there were supplier selections with consideration of the transportation costs and discounts provided by the supplier and there was various demand for various products during $\mathrm{T}$ period. The objective is to select one or more suppliers, determine which period the procurement will take place and the lot size to be purchased during that period.

\subsection{Model Assumption}

The proposed model was limited by several assumptions such as fluctuative and constant demand. Shortages are permitted and backlog are assumed when the total supply available in a given period is insufficient to meet demand in that period. The production capacity of suppliers and the storage capacity of buyers in any period were limited. The delivery trucks each had the same capacity. The transportation costs of each supplier could vary depending on the distance of supplier's location from the manufacturer.

\subsection{Model Parameters and Decision Variables}

Indices

$\mathrm{T} \quad$ Set of time periods; $1,2, \ldots, \mathrm{t}$

$\mathrm{R} \quad$ Set of all-unit price break levels; $1,2, \ldots, \mathrm{r}$

$\mathrm{S} \quad$ Set of suppliers; $1,2, \ldots, \mathrm{S}$

P Set of products; $1,2, \ldots, p$

Parameters

$U P_{t r s p}$ : Unit price of product $\mathrm{p}$ supplied by supplier $\mathrm{s}$ at price break level $r$ in period $t$

$b_{r s p}:$ quantity at which all-unit price break $\mathrm{r}$ occur at supplier $\mathrm{s}$ of product $\mathrm{p}$

$T C_{t s}:$ FTL cost from supplier s to the buyer in period $\mathrm{t}$

$N C_{t s}$ : Contract cost of new supplier $\mathrm{s}$ in period $\mathrm{t}$

$S O C_{t p}$ : Shortage cost per unit of product $\mathrm{p}$ in period $\mathrm{t}$

$C$ : FTL capacity

$D_{t p} \quad:$ Demand of product $\mathrm{p}$ for time period $\mathrm{t}$

$S C_{t s p}:$ Supplier capacity of product $\mathrm{p}$ in period $\mathrm{t}$

$l_{\text {trsp }}$ : Percentage of product delivered late by supplier $\mathrm{s}$ at price break level $\mathrm{r}$ in period $\mathrm{t}$

$d_{t r s p}:$ Percentage of rejected product delivered by supplier s at price break level $r$ in period $t$

$P_{t s p}^{l} \quad$ : Penalty cost for late delivery product $\mathrm{p}$ by supplier $\mathrm{s}$ in period $\mathrm{t}$

$P_{t s p}^{d} \quad: \quad$ Penalty cost for defected product $\mathrm{p}$ by supplier $\mathrm{s}$ in period $\mathrm{t}$

$O_{t s} \quad$ : Cost of ordering for a purchase quantity to supplier $\mathrm{s}$ in period $\mathrm{t}$

$H_{t p} \quad$ : Holding cost of product $\mathrm{p}$ per unit time in period $t$

$M S_{t p}$ : Buyer's storage capacity for product $\mathrm{p}$ in period $\mathrm{t}$

$\varnothing \quad$ : Buyer's service level requirement in period $t$ so $(1-\emptyset)$ is the proportion of buyer's demand that are not met by supplier in period $t$

$M \quad$ : Big number

Decision Variables

$X_{\text {trsp }}$ : Number of product $\mathrm{p}$ supplied by supplier s at price break level $r$ in time period $t$

$S_{t s}:$ Frequency of truck delivered product from supplier $\mathrm{s}$ in period $\mathrm{t}$

$Y_{\text {trsp }}:$ Binary variable used in separating price levels $r$ for product $p$ in a transaction between buyer and supplier $\mathrm{s}$ in period $\mathrm{t}$ 
$Z_{t s}$ : Binary variable ( 1 if an order is placed to supplier $\mathrm{s}$ in period $\mathrm{t}$ and hence order cost is charged, 0 otherwise)

$V_{t s p} \quad$ : Binary variable indicating whether supplier $\mathrm{s}$ is chosen or not in period $t$

$W_{t s} \quad$ : Binary variable for choosing new supplier (1 if a new contract is established with supplier $\mathrm{s}$ in period t, 0 otherwise)

$i_{t p}^{+} \quad:$ Inventory of product $\mathrm{p}$ in period $\mathrm{t}$

$i_{t p}^{-} \quad: \quad$ Shortage of product $\mathrm{p}$ in period $\mathrm{t}$

\subsection{Mathematical Formulation}

With the above parameters and decision variables, the mixed integer non linear program model is expressed as follows:

Minimize $\mathrm{Z}=\mathrm{Z}_{1}+\mathrm{Z}_{2}+\mathrm{Z}_{3}+\mathrm{Z}_{4}+\mathrm{Z}_{5}+\mathrm{Z}_{6}+\mathrm{Z}_{7}+\mathrm{Z}_{8}$

$Z_{1}=\sum_{t=1}^{T} \sum_{r=1}^{R} \sum_{s=1}^{S} \sum_{p=1}^{P} X_{t r s p} * U P_{t r s p}$

$Z_{2}=\sum_{t=1}^{T} \sum_{s=1}^{S} T C_{t s} * S_{t s}$

$Z_{3}=\sum_{t=1}^{T} \sum_{s=1}^{S} o_{t s} * Z_{t s}$

$Z_{4}=\sum_{t=1}^{T} \sum_{s=1}^{S} N C_{t s} * W_{t s}$

$Z_{5}=\sum_{t=1}^{T} \sum_{p=1}^{P} H_{t p} * i_{t p}^{+}$

$Z_{6}=\sum_{t=1}^{T} \sum_{p=1}^{P} S O C_{t p} * i_{t p}^{-}$

$Z_{7}=\sum_{t=1}^{T} \sum_{r=1}^{R} \sum_{s=1}^{S} \sum_{p=1}^{P} P_{t s p}^{d} * d_{t r s p} * X_{t r s p}$

$Z_{8}=\sum_{t=1}^{T} \sum_{r=1}^{R} \sum_{s=1}^{S} \sum_{p=1}^{P} P_{t s p}^{l} * l_{t r s p} * X_{t r s p}$

Subject to:

$i_{(t-1) p}^{+}+\sum_{r=1}^{R} \sum_{s=1}^{S} X_{t r s p}+\sum_{r=1}^{R} \sum_{s=1}^{S} l_{t r s p} X_{(t-1) r s p}-$

$\sum_{r=1}^{R} \sum_{s=1}^{S} l_{t r s p} X_{t r s p}-\sum_{r=1}^{R} \sum_{s=1}^{S} d_{t r s p} X_{t r s p}$

$\geq D_{t p}+i_{(t-1) p}^{-}+i_{t p}^{+}-i_{t p}^{-} \quad \forall t \in T, \forall p \in P$
$\sum_{t=1}^{T} \sum_{r=1}^{R} \sum_{s=1}^{S} X_{t r s p} \geq \sum_{t=1}^{T} D_{t p} \quad \forall p \in P$

$b_{(r-1) s p} Y_{t r s p} \leq X_{t r s p} \leq b_{r s p} Y_{t r s p}$

$\forall t \in T, \forall r \in R, \forall s \in S, \forall p \in P$

$\sum_{r=1}^{R} Y_{\text {trsp }}=V_{t s p} \quad \forall t \in T, \forall r \in R, \forall s \in S, \forall p \in P$

$\left\lfloor\frac{\sum_{p=1}^{P} X_{t r s p}}{C}\right\rfloor \leq S_{t s} \quad \forall t \in T, \forall r \in R, \forall s \in S$

$X_{\text {trsp }} \leq S C_{t s p} \quad \forall t \in T, \forall r \in R, \forall s \in S, \forall p \in P$

$\sum_{p=1}^{P} X_{t r s p} \leq M * Z_{t s} \quad \forall t \in T, \forall r \in R, \forall s \in S$

$i_{t p}^{+} \leq M S_{t p} \quad \forall t \in T, \forall p \in P$

$\sum_{t=1}^{T} Z_{t s} \leq M * W_{t s} \quad \forall s \in S$

$\sum_{t}^{T} i_{t p}^{-} \leq(1-\emptyset) \sum_{t}^{T} D_{t p} \quad \forall p \in P$

$X_{t r s p}, i_{t p}^{+}, i_{t p}^{-} \geq 0$

$Y_{t r s p}, Z_{t s}, V_{t s p}, W_{t s} \in\{0,1\}$

\section{Numerical Example}

The effectiveness of the proposed MILP model was shown through numerical examples. Buyers wanted to buy products for two periods. Firm's demand for each part changed over times due to market fluctuations and customer demand patterns. In the illustration example there are two periods, two price breaks, four suppliers, and three products (2T-2R-4S-3P). Under the same scenario, a re-calculation was performed but with a constant demand of 1000 . Here is an example illustration:

Table 1. Randomly generated data for the first period (2T-2R4S-3P problem)

\begin{tabular}{cccc}
\hline $\mathrm{T}_{1}$ & $\mathrm{P}_{1}$ & $\mathrm{P}_{2}$ & $\mathrm{P}_{3}$ \\
\hline \multirow{2}{*}{$\mathrm{S}_{1}$} & $600,0.08$, & $1000,0.05$, & $2000,0.1$, \\
& $0.01,4,2^{*}$ & $0.021,3,0$ & $0.01,5,3$ \\
\hline \multirow{2}{*}{$\mathrm{S}_{2}$} & $1000,0.12$, & $700,0.13$, & $1500,0.06$, \\
& $0.031,4,1$ & $0.035,3,1$ & $0.02,5,0$ \\
\hline \multirow{2}{*}{$\mathrm{S}_{3}$} & $800,0.07$, & $800,0.14$, & $2000,0.08$, \\
& $0.025,4,4$ & $0.033,3,1$ & $0.03,5,2$ \\
\hline \multirow{2}{*}{$\mathrm{S}_{4}$} & $800,0.07$, & $800,0.1,0.033$, & $2500,0.12$, \\
& $0.025,4,3$ & 3,2 & $0.02,5,0$ \\
\hline $\mathrm{D}$ & 1000 & 1600 & 2200 \\
\hline $\mathrm{MS}$ & 3200 & 4000 & 3000 \\
\hline $\mathrm{H}$ & 2 & 1 & 1 \\
\hline $\mathrm{SOC}$ & 4 & 2 & 3 \\
$* \mathrm{SC}_{\text {tsp }} \mathrm{d}_{\text {trsp }}, 1_{\text {trsp }} \mathrm{P}_{\text {tsp }} \mathrm{P}_{\text {tsp }}^{\mathrm{l}}$ & & \\
\hline
\end{tabular}


Table 2. Randomly generated data for the second period (2T-2R-4S-3P problem)

\begin{tabular}{cccc}
\hline $\mathrm{T}_{1}$ & $\mathrm{P}_{1}$ & $\mathrm{P}_{2}$ & $\mathrm{P}_{3}$ \\
\hline \multirow{2}{*}{$\mathrm{S}_{1}$} & $1200,0.14$, & $1800,0.11$, & $2200,0.13$, \\
& $0.015,5,2^{*}$ & $0.015,7,0$ & $0.02,6,3$ \\
\hline \multirow{2}{*}{$\mathrm{S}_{2}$} & $2000,0.01$, & $1600,0.12$, & $1500,0.15$, \\
& $0.01,5,1$ & $0.01,7,1$ & $0.02,6,0$ \\
\hline \multirow{2}{*}{$\mathrm{S}_{3}$} & $1400,0.08$, & $1200,0.08$, & $1500,0.08$, \\
& $0.005,5,4$ & $0.012,7,1$ & $0.005,6,2$ \\
\hline \multirow{2}{*}{$\mathrm{S}_{4}$} & $1500,0.03$, & $2000,0.12$, & $1500,0.11$, \\
& $0.015,5,3$ & $0.01,7,2$ & $0.01,6,0$ \\
\hline $\mathrm{D}$ & 2500 & 3200 & 4500 \\
\hline $\mathrm{MS}$ & 4500 & 3900 & 5200 \\
\hline $\mathrm{H}$ & 1 & 2 & 1 \\
\hline $\mathrm{SOC}$ & 2 & 3 & 2 \\
\hline $\mathrm{SC}$ & & & \\
tsp $, \mathrm{d}_{\text {trsp }}, 1_{\text {trsp }}, \mathrm{P}_{\text {tsp }}^{\mathrm{d}}, \mathrm{P}_{\text {tsp }}$ & &
\end{tabular}

Table 3. The values of UP, TC, O, NC, D, MS, H and SOC for the first period (2T-2R-4S-3P problem)

\begin{tabular}{|c|c|c|c|c|c|c|c|c|c|}
\hline \multicolumn{7}{|c|}{ UP } & \multirow{3}{*}{$\mathrm{TC}$} & \multirow{3}{*}{$\mathrm{O}$} & \multirow{3}{*}{$\mathrm{NC}$} \\
\hline & \multicolumn{3}{|c|}{$\mathrm{R}_{1}$} & \multicolumn{3}{|c|}{$\mathrm{R}_{2}$} & & & \\
\hline $\mathrm{T}_{1}$ & $P_{1}$ & $\mathrm{P}_{2}$ & $P_{3}$ & $\mathrm{P}_{1}$ & $P_{2}$ & $\mathrm{P}_{3}$ & & & \\
\hline $\mathrm{S}_{1}$ & 30 & 15 & 30 & 27 & 13 & 28 & 600 & 280 & 520 \\
\hline $\mathrm{S}_{2}$ & 35 & 14 & 22 & 33 & 13 & 20 & 750 & 360 & 680 \\
\hline $\mathrm{S}_{3}$ & 32 & 20 & 25 & 29 & 18 & 23 & 650 & 315 & 570 \\
\hline $\mathrm{S}_{4}$ & 35 & 22 & 30 & 32 & 19 & 27 & 650 & 310 & 575 \\
\hline
\end{tabular}

Table 4. The values of UP, TC, O, NC, D, MS, H and SOC for the second period (2T-2R-4S-3P problem)

\begin{tabular}{|c|c|c|c|c|c|c|c|c|c|}
\hline & \multicolumn{6}{|c|}{ UP } & \multirow{3}{*}{$\mathrm{TC}$} & \multirow{3}{*}{$\mathrm{O}$} & \multirow{3}{*}{$\mathrm{NC}$} \\
\hline & \multicolumn{3}{|c|}{$\mathrm{R}_{1}$} & \multicolumn{3}{|c|}{$\mathrm{R}_{2}$} & & & \\
\hline $\mathrm{T}_{1}$ & $P_{1}$ & $\mathrm{P}_{2}$ & $P_{3}$ & $P_{1}$ & $\mathrm{P}_{2}$ & $\mathrm{P}_{3}$ & & & \\
\hline$S_{1}$ & 40 & 25 & 40 & 37 & 22 & 39 & 1000 & 490 & 920 \\
\hline $\mathrm{S}_{2}$ & 45 & 24 & 32 & 40 & 23 & 34 & 1200 & 590 & 1125 \\
\hline $\mathrm{S}_{3}$ & 42 & 30 & 35 & 41 & 25 & 34 & 1500 & 730 & 1420 \\
\hline $\mathrm{S}_{4}$ & 45 & 32 & 40 & 43 & 30 & 36 & 1200 & 580 & 1125 \\
\hline
\end{tabular}

Table 5. Final result of supplier assignment and quantity supplied for the respective product (2T-2R-4S-3P problem).

\begin{tabular}{|c|c|c|c|c|c|c|c|c|c|}
\hline & & \multicolumn{4}{|c|}{$\mathrm{R}_{1}$} & \multicolumn{4}{|c|}{$\mathrm{R}_{2}$} \\
\hline & & $\mathrm{S}_{1}$ & $\mathrm{~S}_{2}$ & $\mathrm{~S}_{3}$ & $\mathrm{~S}_{4}$ & $\mathrm{~S}_{1}$ & $\mathrm{~S}_{2}$ & $\mathrm{~S}_{3}$ & $\mathrm{~S}_{4}$ \\
\hline \multirow{3}{*}{$\mathrm{T}_{1}$} & $\mathrm{P}_{1}$ & 600 & 800 & 800 & 0 & 0 & 0 & 0 & 800 \\
\hline & $\mathrm{P}_{2}$ & 1000 & 700 & 700 & 616 & 0 & 0 & 0 & 0 \\
\hline & $\mathrm{P}_{3}$ & 0 & 0 & 0 & 284 & 2000 & 1500 & 2000 & 0 \\
\hline \multirow{3}{*}{$\mathrm{T}_{2}$} & $P_{1}$ & 340 & 160 & 0 & 0 & 0 & 0 & 0 & 340 \\
\hline & $\mathrm{P}_{2}$ & 0 & 0 & 0 & 0 & 1000 & 900 & 0 & 0 \\
\hline & $\mathrm{P}_{3}$ & 216 & 700 & 0 & 0 & 0 & 0 & 0 & 216 \\
\hline
\end{tabular}

Table 6. Final result of supplier assignment and quantity supplied for the respective product (2T-2R-4S-3P problem) with a constant demand

\begin{tabular}{|c|c|c|c|c|c|c|c|c|c|}
\hline & & \multicolumn{4}{|c|}{$\mathrm{R}_{1}$} & \multicolumn{4}{|c|}{$\mathrm{R}_{2}$} \\
\hline & & $\mathrm{S}_{1}$ & $\mathrm{~S}_{2}$ & $\mathrm{~S}_{3}$ & $\begin{array}{l}S \\
4\end{array}$ & $\mathrm{~S}_{1}$ & $\mathrm{~S}_{2}$ & $\mathrm{~S}_{3}$ & $\begin{array}{l}\mathrm{S} \\
4\end{array}$ \\
\hline \multirow{6}{*}{$\mathrm{T}$} & $P$ & 60 & 60 & 80 & 0 & 0 & 0 & 0 & 0 \\
\hline & 1 & 0 & 2 & 0 & 0 & $\tilde{U}$ & 0 & 0 & 0 \\
\hline & $P$ & 0 & 69 & 31 & 0 & 100 & 0 & 0 & 0 \\
\hline & 2 & 0 & 8 & 9 & 0 & 0 & 0 & 0 & 0 \\
\hline & $\mathrm{P}$ & 0 & 0 & 0 & 0 & 0 & 100 & 100 & 0 \\
\hline & 3 & & & 0 & & & 0 & 0 & \\
\hline \multirow{4}{*}{$\mathrm{T}$} & $\mathrm{P}$ & 0 & 0 & 0 & 0 & 0 & 0 & 0 & 0 \\
\hline & $\mathrm{P}$ & 0 & 0 & 0 & 0 & 0 & 0 & 0 & 0 \\
\hline & 2 & & & & & & & & \\
\hline & $P$ & 0 & 0 & 0 & 0 & 0 & 0 & 0 & 0 \\
\hline
\end{tabular}

The results for the above scenarios are listed in Table 5. From Table 5 we can see that in period one all suppliers supplied the product. Product one was supplied by $\mathrm{S}_{1}, \mathrm{~S}_{2}$ and $S_{3}$ at the first price break level and $S_{4}$ at the second price break level. Product two was supplied by $\mathrm{S} 1, \mathrm{~S}_{2}, \mathrm{~S}_{3}$ and $\mathrm{S}_{4}$ at the first price break level. And product three was supplied by $S_{4}$ at first price break and $S_{1}, S_{2}$ and $S_{3}$ at second price break level. Period two was only supplied by $\mathrm{S}_{1}, \mathrm{~S}_{2}$, and $\mathrm{S}_{4}$ with the allocation of products shown on the table. The value of the objective function for that model was 472476,5 .

In the second calculation result shown by Table 6 , it is shown that only $S_{1}, S_{2}$ and $S_{3}$ supply product 1,2 and 3 . It is seen that there are more number of units allocated. In the second period, order is not necessary as it tends to store inventory in the first period.

\section{Conclusion}

In this paper, the supplier selection problem was solved by MILP mathematical model. Numerical illustration with scenario 2T-2R-4S-3P and a second experiment was used to demonstrate the model. The second experiment used the same value for all parameters except the demand parameter using a constant value of 1000. Optimization solved for less than 10 seconds using LINGO 16. When the demand was fluctuating, all suppliers contributed in supplying products, and when it was constant there were only a few suppliers who shipped products and prefered to store inventory in the first period. This model can be applied in real conditions. The resulting random data can be replaced with real time data. However, the number of periods, products, and suppliers used were limited because Lingo software was unable to solve high complexity problems. Therefore, further research can develop this model using heuristic methods to solve more complex problems. 


\section{References}

1. Aguezzoul, A., \& Ladet, P. (2007). A nonlinear multiobjective approach for the supplier selection, integrating transportation policies. https://doi.org/10.1108/17465660710763434

2. Aissaoui, N., Haouari, M., \& Hassini, E. (2007). Supplier selection and order lot sizing modeling: A review. Computers and Operations Research, 34(12), 3516-3540. https://doi.org/10.1016/j.cor.2006.01.016

3. Burke, G. J., Carrillo, J. E., \& Vakharia, A. J. (2007). Single versus multiple supplier sourcing strategies, 182 , 95-112. https://doi.org/10.1016/j.ejor.2006.07.007

4. Cakravastia, A., \& Takahashi, K. (2004). Integrated model for supplier selection and negotiation in a make-to-order environment. International Journal of Production Research, 42(21), 4457-4474. https://doi.org/10.1080/00207540410001727622

5. Cárdenas-Barrón, L. E., González-Velarde, J. L., \& Treviño-Garza, G. (2015). A new approach to solve the multi-product multi-period inventory lot sizing with supplier selection problem. Computers \& Operations Research, 64, 225-232. https://doi.org/10.1016/j.cor.2015.06.008

6. Chaudhry, S. S., Forst, F. G., \& Zydiak, J. L. (1993). Vendor selection with price breaks. European Journal of Operational Research, 70(1), 52-66. https://doi.org/10.1016/0377-2217(93)90232-C

7. Choudhary, D., \& Shankar, R. (2011). Modeling and analysis of single item multi-period procurement lotsizing problem considering rejections and late deliveries. Computers and Industrial Engineering, 61(4), 1318-1323. https://doi.org/10.1016/j.cie.2011.08.005

8. Choudhary, D., \& Shankar, R. (2013). Joint decision of procurement lot-size, supplier selection, and carrier selection. Journal of Purchasing and Supply Management, 19(1), 16-26. https://doi.org/10.1016/j.pursup.2012.08.002

9. Demirtas, E. A., \& Üstün, Ö. (2008). An integrated multiobjective decision making process for supplier selection and order allocation. Omega, 36(1), 76-90. https://doi.org/10.1016/j.omega.2005.11.003
10. Liao, Z., \& Rittscher, J. (2007). Integration of supplier selection, procurement lot sizing and carrier selection under dynamic demand conditions, 107, 502-510. https://doi.org/10.1016/j.ijpe.2006.10.003

11. Lin, J. R., \& Lei, H. C. (2009). Distribution systems design with two-level routing considerations. Annals of Operations Research, 172(1), 329-347. https://doi.org/10.1007/s10479-009-0628-y

12. Masella, C., \& Rangone, A. (2000). A contingent approach to the design of vendor selection systems for different types of co-operative customer/ supplier relationships. International Journal of Operations \& Production Management, 20(1), 70-84.

13. Rezaei, J., \& Davoodi, M. (2011). Multi-objective models for lot-sizing with supplier selection. International Journal of Production Economics, $130(1)$, $77-86$. https://doi.org/10.1016/j.ijpe.2010.11.017

14. Sagar, M., \& Singh, D. (2012). Supplier Selection Criteria: Study of Automobile Sector in India. International Journal of Engineering Research and Development, 4(4), 34-39. Retrieved from http://scholar.google.com/scholar?hl=en\&btnG=Sea rch\&q=intitle:Supplier+Selection+Criteria+:+Study + of + Automobile+Sector+in+India\#0

15. Shinn, S. W., Hwang, H., \& Park, S. S. (1996). Joint price and lot size determination under conditions of permissible delay in payments and quantity discounts for freight cost. European Journal of Operational Research, 91(3), 528-542. https://doi.org/10.1016/0377-2217(94)00357-2

16. Ware, N. R., Singh, S. P., \& Banwet, D. K. (2014). Expert Systems with Applications A mixed-integer non-linear program to model dynamic supplier selection problem. Expert Systems With Applications, 41(2), 671-678. https://doi.org/10.1016/j.eswa.2013.07.092

17. Wicaksono. (2016). Supplier Selection Model Considering Truckload Shipping. 